\title{
The Biochemical Effects of Angiotensin-(1-7) on the Oxidative Stress Metabolism and Their Specific Parameters from the Temporal Lobe
}

\author{
SORIN UNGURIANU ${ }^{1}$, CONSTANTIN TRUS ${ }^{2 *}$, ROXANA-ROSMARY ENCIU $^{3}$ \\ ${ }^{1}$ Faculty of Medicine, Dunarea de Jos University, Galati, Romania \\ ${ }^{2}$ Department of Morphological and Functional Sciences, Faculty of Medicine, Dunarea de Jos Uiversity, Galati, Romania \\ ${ }^{3}$ Sf. Apostol Andrei, Emergency Clinical Hospital, 188 Brailei Str., 800494, Galati, Romania
}

\begin{abstract}
It is already known from a variety of previous reports that an independent brain reninangiotensin system (RAS) exists, completely separated from the one in the periphery. This independent brain RAS has all the precursors and the enzymatic structures necessary for the generation of the angiotensin peptides. Thus, in the last few years various groups started focusing on the more central effects of less known angiotensins (e.g in comparison with Angiotensin (Ang) II), namely Ang III, Ang IV, Ang-(1-7) or Ang 5-8. One of these newly emerging angiotensins which has become an increased center of interest in many studies is Ang-(1-7), which is a heptapeptide previously described especially for its opposite effects to Ang II, in the peripheral vascular area, but also described for some opposite central functions vs. Ang II. These aspects are completed with the fact that it was recently suggested that the renin-angiotensin system could modulate the oxidative stress metabolism, and also it seems that the manifestations of Angiotensin-(1-7) on the basal oxidative stress status are contradictory, with a variety of reports describing controversial (e.g. both pro-oxidant and antioxidant actions) effects for this heptapeptide. Our results presented here are confirming a possible antioxidant effect of Ang-(1-7) administration on rat, as shown by the increased levels of antioxidant enzymes from the temporal lobe (superoxide dismutase and glutathione peroxidase) and decreased levels of malondialdehyde, as an important lipid peroxidation parameter.
\end{abstract}

Keywords: angiotensin-(1-7), oxidative stress, superoxide dismutase, glutathione peroxidase, malondialdehyde

\section{Introduction}

As it was demonstrated in a multitude of previous reports that there is an independent brain reninangiotensin system (RAS), completely separate from the one in the periphery, which also has all the precursors and the enzymatic structures necessary for the generation of the angiotensin peptides, in the last few years various groups started focusing on the more central effects of less known angiotensins (e.g. in comparison with Angiotensin (Ang) II), namely Ang III, Ang IV, Ang-(1-7) or Ang 5-8 [1].

In this way, the specific peptides were previously cited for being implicated in the general cognitive functions, with focus being especially concentrated on the affective or nociceptive processes [1], but also in relation to the oxidative stress status/metabolism [2], as we will insist immediately.

Thus, one of these newly emerging angiotensins which has become an increased center of interest in many studies is Ang-(1-7), which is a heptapeptide previously described especially for its opposite effects to Ang II, in the peripheral vascular area, but also described for some central antagonic functions vs. Ang II [3]. In addition, these opposite effects were also expressed in regards to the oxidative stress metabolism [2] (as we will try to demonstrate in the present research mini-report).

\footnotetext{
*email:dilconstantin@yahoo.com
} 
Thus, as mentioned, these aspects are completed with the fact that it was recently suggested that the renin-angiotensin system could modulate the oxidative stress metabolism [2], and also it seems that the manifestations of Angiotensin-(1-7) on the basal oxidative stress status are contradictory, with a variety of reports describing controversial pro-oxidant [4] and antioxidant [5] actions for this special heptapeptide.

In the aforementioned context, in the present mini-report we were interested in studying the modulatory effects of Ang-(1-7) administration on the main oxidative stress parameters from the temporal lobe such as two antioxidant enzymes (superoxide dismutase-SOD and glutathione peroxidase-GPX) and a lipid peroxidation marker (malondialdehyde-MDA) of experimental Wistar rats.

\section{Material and methods}

We used 5 Wistar rats per group ( $\mathrm{n}=10$, since we only had 2 groups: a control which received saline and an Ang-(1-7)-treated group), with an age of around 3 months \pm a few days (maximum 7), being kept in laboratory conditions (normal laboratory room temperature, humidity, and 12/12 hours light/dark cycle), with permanent access to food and water. Angiotensin-(1-7) was obtained from Merck, Darmstadt, Germany.

The animals were treated in accordance with the guidelines of animal bioethics from the Act on Animal Experimentation and Animal Health and Wellfare Act from Romania and all procedures were in compliance with the European Communities Council Directives. This study was approved by the local Ethics Committee (approval number 385/04.04.2019) and we also made efforts to minimize animal suffering and the general number of animals used.

\section{Treatment}

The treatment was delivered during one-minute period time, intraperitoneal. The control rats were injected with saline. Dosing of Ang-(1-7) was $2 \mu \mathrm{L}$ in $1 \mathrm{~min}$.

After decapitation, the entire temporal lobes were collected.

\section{Biochemical assays}

Biochemical assays performed after that included the determination of SOD (e.g. through a specific kit from Sigma Aldrich, no. 19160), the determination of GPX (e.g. through a specific kit from Sigma Aldrich, no. CGP-1) and lastly the determination of MDA, (by a classical thiobarbituric acid reactive substances assay, by using the trichloroacetic acid and thiobarbituric acid-related method (for further details please see [12]).

For both antioxidant enzymes the values were normalized by mg protein (determined though Bradford method) and presented as enzymatic activity units.

\section{Data analysis}

The levels of oxidative stress markers were statistically analyzed by using Student's t-test (two tailed, unpaired). All results are expressed as mean value \pm standard deviation. $\mathrm{P}<0.05$ was regarded as statistically significant.

\section{Results and discussions}

Thus, our initial biochemical assessment showed significant increase in the specific activity of SOD (expressed in Enzymatic Units), as the first antioxidant enzyme in the way of the free radicals, as compared to the control group $(\mathrm{p}<0.05)$ (Figure 1). 


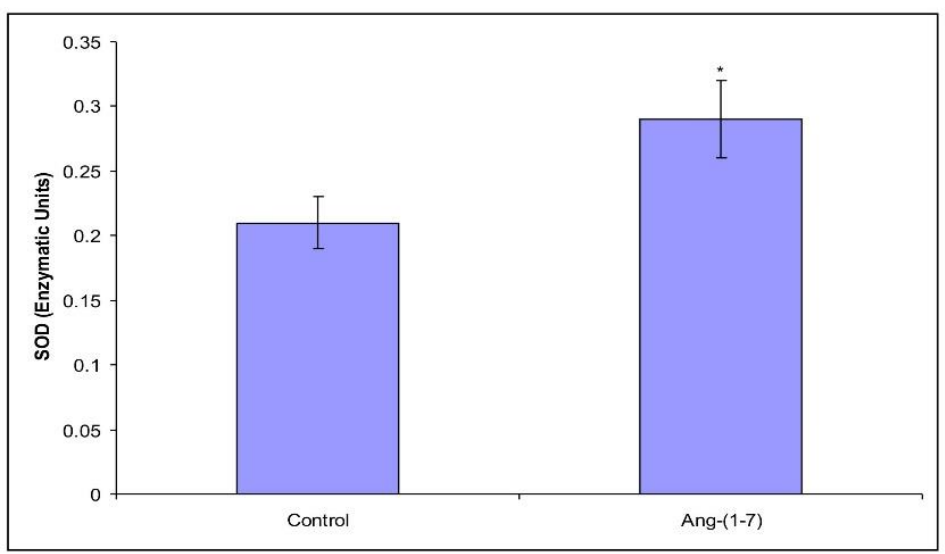

Figure 1. The effects of

Angiotensin-(1-7)

administration

on SOD specific activity.

$* \mathrm{p}<0.05$, as compared to control group. Values are expressed as unit's/mg protein

Somehow, similar pathway was observed also for the second antioxidant enzyme we determined in this experiment, represented by GPX, which was also significantly increased $(p<0.05)$ in the angiotensin-(1-7), as compared to the controls (Figure 2).

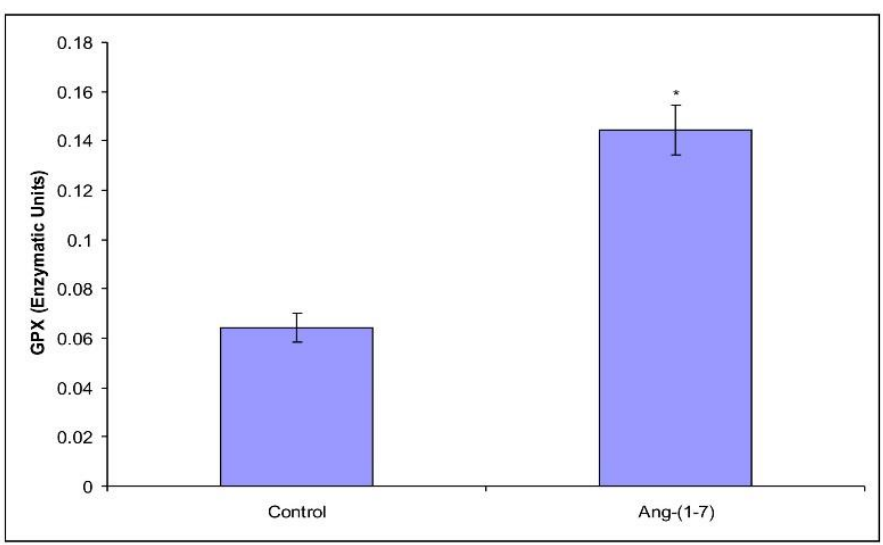

Figure 2. The effects of Angiotensin-(1-7) administration on GPX specific activity.

$* \mathrm{p}<0.05$, as compared to control group.

Values are expressed as unit's/mg protein

The possible antioxidant actions of Angiotensin-(1-7) were also confirmed by the very significant decrease in the MDA concentration of the Ang-(1-7) treated rats, when compared to the controls $(\mathrm{p}<0.05)$, as an important lipid peroxidation marker (Figure 3 ).

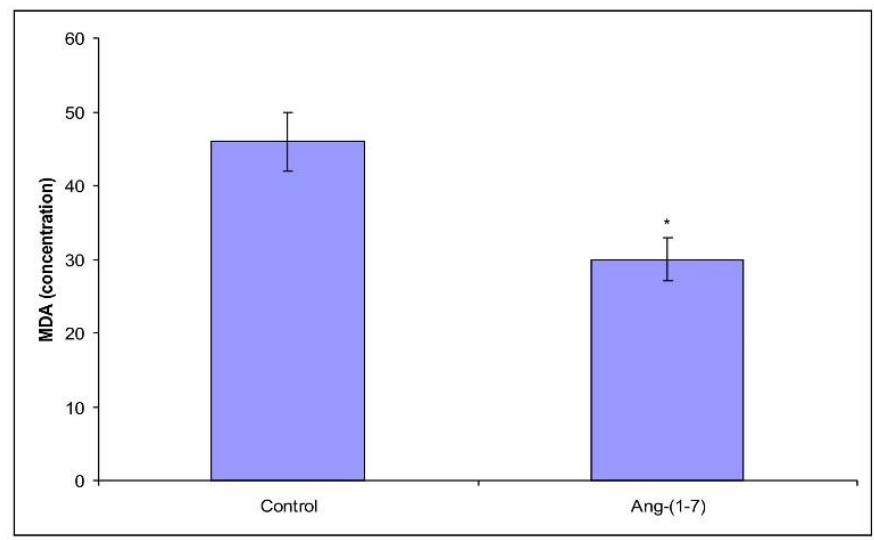

Figure 3. The effects of Angiotensin-(1-7) administration on MDA concentration. $* \mathrm{p}<0.05$, as compared to control group. Values are expressed as $\mathrm{nM} / \mathrm{mg}$ protein

Our results presented here are confirming a possible antioxidant effect of Ang-(1-7) administration on rat, as demonstrated by increased levels of antioxidant enzymes (SOD and GPX) and decreased levels of MDA (an important lipid peroxidation parameter) in the temporal lobe of Wistar rats.

In fact, when it comes to the previous effects of Ang-(1-7) administration on oxidative stress status, the results are very diverse, with previous reports describing that Ang-(1-7) can decrease ischemia 
reperfusion-mediated oxidative stress by modulating the levels of MDA and is also decreasing the specific enzymatic activity of SOD [4]. Also, opposite results were described, for example in the report of a Chinese research group lead by Liao et al, [6] which demonstrated clear prooxidant actions (e.g. it reduces SOD and GPX specific enzymatic activity + it decreases glutathione levels).

Additionally, it was previously showed that Ang-(1-7) could decrease the oxidative stress generated by the renal NADPH oxidase in diabetic hypertensive rats [7] and it can decrease ischemia reperfusion-generating increased oxidative stress metabolism, through the modulation of other two oxidative stress-parameters we already described in the present report (e.g. by decreasing SOD enzymatic activity and the concentrations of MDA) [6].

In addition, in a report from 2002, other group working in this area of research [4] showed an increase in the oxidative stress metabolism (e.g. decreased SOD and GPX values), while catalase, the other antioxidant enzyme implicated, showed no significant modifications in its activity [4].

All these effects can be also connected to the complex relations that exist between these complex peptides of the brain Renin-Angiotensin system (brain RAS), for example Polizio group [8] showed that Ang II effects on increasing the concentration of superoxide free radical are inhibited by Ang-(17) administration, suggesting that the heptapeptide could diminish the increasing oxidative processes generated by Angiotensin II.

In the same way, the Jiang group [9] experimentally showed that Ang-(1-7) could decrease the oxidative stress metabolism manifestations in hypertension-related pathological manifestations, by focusing on another two markers, such as the levels of Bax and Bcl-2 [9].

In this way, what it is very important in the context of our present mini-report (since we concentrated some of our efforts here in working in the temporal lobe of the experimental rats) is the fact that the specific Mas receptors are expressed in several brain regions related to our present concerns such as the: hippocampus, the piriform cortex, olfactory bulb and amygdala [10].

What we also mention is the fact that although the modulation of memory, pain, anxiety or the depressive-like symptoms by the angiotensin-(1-7) were previously described [1], behavioral data regarding these complex peptides are still very scarce and difficult to integrate. However, since there is a strong and clear connection between oxidative stress parameters and the cognitive functions [11], further studies are important also in order to elucidate the functions for the cognitive effects of angiotensin-(1-7), in relation or not with the oxidative stress metabolism and antioxidants. This also implies very complex mechanisms related to exercising [12], biophysical [13, 14] or surgical-induced $[15,16]$ manifestations to be further discussed and developed (in relation also to our previous work which we described in other occasions [17-20]).

\section{Conclusions}

Our results presented here describe a possible antioxidant effect of Ang-(1-7) administration on rat, as shown by increased levels of antioxidant enzymes from the temporal lobe (superoxide dismutase and glutathione peroxidase) and decreased concentrations of malondialdehyde, as an important lipid peroxidation parameter in Wistar laboratory rats.

\section{References}

1. VON BOHLEN UND HALBACH, O., ALBRECHT, D. Cell Tissue Res., 326, 2006, p. 599.

2. HITOMI, H., KIYOMOTO, H., NISHIYAMA, A. Curr Opin Cardiol. 22, 2007, p. 311.

3. CLARK, M., DIZ, D., TALLANT, E. Hypertension. 37, 2001, p. 1141.

4. GONZALES, S., NORIEGA, G., TOMARO, M., PEÑA, C. Regulatory peptides. 106, 2002, p 67.

5. LIU, C., LV, X., LI, H., CAO, X., ZHANG, F., WANG, L., YU, M., YANG, J. Acta Diabetol. 49, 2012, p. 291.

6. LIAO, X., GUO, R., MA, H., WANG, L., CHEN, Z., YANG, C., FENG. J. Nan Fang Yi Ke Da Xue Xue Bao. 28, 2008, p. 1345.

7. BENTER, I., FERRARIO, C., MORRIS, M., DIZ, D. Am J Physiol. 269, 1995, p. 313. 
8. POLIZIO, A., GIRONACCI, M., TOMARO, M., PENA, C. Pharmacol Res. 56, 2007, 86-90.

9. JIANG, T., GAO, L., SHI, J., LU, J., WANG, Y., ZHANG, Y. Pharmacol Res. 67, 2013, p. 84.

10. OSCAR, C., MÜLLER-RIBEIRO, F., DE CASTRO, L., MARTINS LIMA, A., CAMPAGNOLESANTOS, M., SANTOS, R., XAVIER, C., FONTES, M. Brain Res. 1594, 2015, p.183.

11. HAJJAR, I., HAYEK, S., GOLDSTEIN, F., MARTIN, G., JONES, D., QUYYUMI, A. Journal of Neuroinflam. 15, 2018, p. 17.

12. TROFIN, F., CIOBICA, A., HONCERIU, C. COJOCARU, S. STOICA, B., COJOCARU, D., CIORNEA, E., TIMOFTE, D. Romanian Biotechnological Lett. 22, 2017, p. 12439.

13. ANTON, E., ROTARU, A., COVATARIU, D., CIOBICA A., TIMOFTE D., POPESCU, R., ANTON, C. Archives of Biological Sciences Belgr. 67, 2015, p. 895.

14. AURSULESEI, V., VASINCU, D., TIMOFTE, D., VRAJITORIU, L., GATU, I., IACOB, D.D., GHIZDOVAT, V., BUZEA, C., AGOP, M. Gen Physiol Biophys. 35, 2016, p. 287.

15. IOV, T., TIMOFTE, D., DAMIAN, S.I., KNIELING, A., SCRIPCARU, C., ILIESCU B. Rom J Leg Med. 26, 2018, p. 141.

16. TIMOFTE, D., CIUNTU, B., BULGARU ILIESCU, D., HAINAROSIE, R., PANTEA STOIAN, A., MOCANU, V. Revista de Cercet. si Interven. Soc., 61, 2018, p. 147.

17. STATESCU, C., HONCERIU, C., JURCAU, R., TRUS, C., Rev. Chim., 70(11), 2019, 4102.

18. STATESCU, C., HONCERIU, C., TRUS, C., REVISTA DE CHIM. 70, 2019, p 3579.

19. PREPELITA, R. CRISTOFOR, A., DOBRIN, R., TRUS, C., CIOBICA, A., CHIRITA, R., Rev. de Cercet. si Interven. Soc. 65, 2019, p. 111.

20. STAMATE, M.I., STAMATE, C., TIMOFTE, D., CIUNTU, B., GAFITANU, C., STEFANACHE, A., OCHIUZ, L., Mater. Plast., 56(1), $2019,244$.

$\overline{\text { Manuscript received: } 26.034 .2020}$ 